\title{
Promotion Mechanism of Ganpo Local Culture's “Going-out” Strategy
}

\author{
Pingrong Tu, Suqin Zhou
}

Yichun University, Yichun, 336000, China

\begin{abstract}
Keywords: Ganpo Local Culture, "Going-out" Strategy, Promotion Mechanism
\end{abstract}
\begin{abstract}
Ganpo local culture is one shining star among Chinese local culture, which has bred and accumulated profound local culture for Ganpo. These local cultures have also vigorously promoted the development of economic society in Jiangxi. However, Ganpo local culture has not enjoyed high reputation or influence throughout the country at present. To go out, it has been confronted by many problems, including insufficient capital, weak marketization, insufficient governmental supervision and defective cultural innovations. Therefore, to implement the "going-out" strategy of Ganpo local culture, it must vigorously promote the "going-out" strategy, from theses perspectives, respectively are expanding capital investment mechanism, promoting market operation mechanism, improving governmental supervision mechanism, strengthening opening and cooperation mechanism and promoting cultural innovative mechanism.
\end{abstract}

\section{Introduction}

Jiangxi has a long history, prosperous humanity and profound cultural deposits. As a big agricultural province, Ganpo does not only possess the unique natural resources for agricultural development, but also profound local culture resources. Under the guidance of advocating the loud slogan of creating a powerful cultural province, local culture has manifested its strong vitality to promote the economic development of Jiangxi, as the "soft power" for economic and social development of Ganpo. According to relevant data, there were more than 10000 "agritainment" in Jiangxi in 2012, which promoted 360000 peasants to get jobs; Jiangxi received more than 10 million tourists per year, with a comprehensive revenue of more than 6 billion yuan. The rise of "agritainment" in Ganpo has played a quite important role in adjusting the rural industrial structure of Jiangxi, increasing the income of local peasants and promoting the rural economic development. ${ }^{[1]}$

Meanwhile, Ganpo local culture also has quite profound humanistic connotations. In the aspect of enriching the spiritual and cultural life of peasants, it has also performed a good development trend. Yudu county of Gannan has already got more than 120 local villages with folk culture, such as Suona village, Flower-drum village, Colored-lantern village, Puppet village, Calligraphy village, etc. There are over 80 mass culture groups and 400 major cultural households. Colorful local culture enables the mass to be educated subtly. [2] "Chunluo" culture of Ganxi Pingxiang still has dense local flavor and sentiments, which is valuable treasure of folk art. In 1998, on behalf of Jiangxi Team, "Chunluo" participated in The $3^{\text {rd }}$ Opera \& Drama Festival of China held in Hohhot. In 2002, it also participated in The $4^{\text {th }}$ Opera \& Drama Festival of China held in Beijing, on behalf of JIangxi Team. They received quite good praise. Several years ago, related department recorded the tapes of "Chunluo" for the first time and then promoted that around China, which was warmly welcomed by many citizens. ${ }^{[3]}$

On March $1^{\text {st }}$, 2014, Beijing • Jiangxi Cultural Month was opened in Beijing, which enabled a lot of national cultural relics of Jiangxi to walk out of Jiangxi and appear in the capital. It broke the situation that Jiangxi local culture was "kept in the deep purdah and nobody knew", which was an important milestone for Jiangxi local culture to go out of the province. However, Jiangxi is located in the middle parts of China, which still belongs to under-development area. There are still quite large urban-rural gap and industrial-agricultural gap. To "go out”, local culture has been still confronted by the realistic difficulties, including insufficient capital, weak marketization, insufficient governmental supervision and defective cultural innovations. Consequently, how to make the best use of the circumstances, walk out of the dilemma, implement the "going out" development strategy of Ganpo 
local culture and promote the long-term social and economic development of Jiangxi, it has profound and significant significance.

\section{Expanding the Mechanism of Capital Investment}

Ganpo local culture has derived and grown up in under-development rural areas. Due to the weak economic foundation, the principal difficulty confronted by Ganpo during the "going-out" process is the insufficient capital. Culture needs to be packaged, which cannot produce the great degree of understanding or influential power unless the culture is put into the market. Cultural packaging needs the capital investment. Government needs to increase more financial investments on rural cultural programs with development prospect and potentials; lead social idle capital to the development of Ganpo local culture; attract relevant enterprises to participate in development programs of Ganpo local culture; encourage and guide all kinds of financial organizations to reinforce the "going-out" financing of Ganpo local culture enterprises and programs, and also promote eligible Ganpo local culture enterprises to seek financing by listing on the stock market; the government should strongly support the influential local cultural programs, such as the capital, tax, etc. For instance, Le'an County integrated more than 2 million yuan through multi-channels, so as to help Donghu village of Zengtian town to reconstruct ancient temple of God Nuo(driving away pestilence), build a new opera stage for Liukeng village, and also add a lot of props and audio equipment for Huping Story-telling Festival, Luobei Temple Fair and Liukeng fair, which has greatly improved the performing conditions of local culture. [4] These investments can effectively promote the development of Ganpo local culture and improve the "going-out" competitiveness of Ganpo local culture.

Part Two Promoting Market Operation Mechanism

Cultural market operation mechanism refers to the form of basic economic relationship and interaction among all cultural markets' main bodies and objectives, which mainly exist in the form of cultural-economic relationship. It adjusts the allocation of cultural resources. Cultural market operation mechanism is the process system and method system of interactions and mutual effect of cultural market's supply-demand relationship, price movement and market competition specified and influenced by the law of value. ${ }^{[5]}$ Market is the dynamic reflection of social demands. Grasping the market is equal to grasp the social demands. ${ }^{[6]}$ Therefore, the government departments should develop a series of policies, adopt corresponding measures and methods to attract foreign businesses and investment, reinforce the publicity by internet, further to promote the brand of local culture to the outside world. Moreover, cultural backbones can be dispatched to the grass-roots for making investigations. They could investigate local culture conforming to the demands and flavors of the ordinary people, and then make great investments and promotions. Since this year, all kinds of folk literary and artistic groups in Gan County have provided more than 600 performances in rural areas. Some traditional shows have been recorded and broadcast by CCTV, including "Tiancun festive lantern" and "dragon dance on stilts". ${ }^{[7]}$ By devoting great efforts to exploring the unique charm of Ganpo local culture, further to expand the overseas market, it can give touring performances for overseas Chinese and let them generate resonance, further to produce certain influence and let overseas Chinese inherit and communicate Ganpo local culture in other foreign countries. For instance, Jiangxi Acrobatic Troupe have successively performed for 500 times in over 40 countries, including America, Canada, England, etc, attracted more than 600000 audiences and realized the revenue of 3720000 yuan. Tea, the acrobatic show of Jiangxi, has been performed in Shanghai World Expo for 184 times, attracting more than 300000 audiences. In 2011, Jiangxi Song and Dance Theater presented more than 20 shows, which included the excellent play of large-scale folk dance Gan Style, with an income of more than 2 million yuan. ${ }^{[8]}$

\section{Improving the Governmental Supervision Mechanism}

To realize the "going-out" strategy of Ganpo local culture, it still needs to fatherly improve the governmental supervision mechanism. Concrete measures are as follows: first of all, it should take full advantage of the Medias to enhance the propaganda, such as opening a special column on the 
information website of government, further to deeply publicize laws and regulations about management of related cultural markets. By straighten outing the management mechanism and improving related legal institutions, it should normalize financial input, special fund for specified purpose, industrial planning, construction land, approval formalities, tax policies and talent cultivation of local culture; secondly, it should elaborately study the products with local culture, develop evaluation method of local culture assets, improve the evaluation system of local culture assets and vigorously promote the effective integration of local culture industry and financial capital; thirdly, it should establish and improve classification standard, data statistical system and database of foreign cultural trade of local culture industry, so as to offer effective service for the government to develop cultural development policies and enterprises' decisions; fourthly, it should strictly examine the contents of local culture, reserve the parts beneficial for the inheritance of traditional cultural spiritual civilization while eliminating minority of cultural dross. The appearance of local culture has greatly enriches the spiritual life of peasants. For instance, the government has set up the special fund for local culture, which offers powerful economic guarantee for the inheritance of local culture. By setting up rural theaters and peasants' center for cultural activities, these sites communicating culture can let native competent people with local culture perform their professional skills. Besides, the old who stay behind for a long time can enjoy the pleasure brought by local culture. Peasant laborers no longer play mahjong or poker after returning to the hometown, but enrich and fulfill their spiritual life in local cultural locations. In addition, the "left-behind" children can be well educated.

\section{Enlarging the Opening and Cooperation Mechanism}

Opening creates chance, cooperation fulfills dream. Jiangxi possesses the historical accumulation of opening and win-win, cooperation and opening. Once upon a time, Jiangxi businessmen stood like a tripod and overrun the four seas for more than 900 years. It was called that "If boats of South Jiangxi cannot be seen for three days, the grain shortage will appear on the earth”. As is known to all, as an important commodity on the Maritime Silk Road, porcelains of Jiangxi Jingdezhen have closely connect the trades of Ganpo with various countries in the world, which has created the open economic pattern of Jiangxi. However, recently, Ganpo local culture has insufficient reputation and influence overseas, even in China, which is closely related to the situation that Jiangxi has advocated to devote major efforts to developing economy during the rise of middle parts, and then neglected the development and utilization of the valuable spiritual wealth--local culture. In addition, Jiangxi has not been brave enough to cooperate with central interior provinces, which is not so active to take part in international exhibitions. How should Ganpo local culture "go out"? The author thinks that it should excavate the essence of Jiangxi local culture and find out the culture representing local characteristics of Ganpo. It can refer to Zhao Benshan's promotion of northeast song-and-dance duet, the comedy skit. By cooperating with traditional and influential medias, taking advantage of some portal and local satellite TV platform, it can open a special column for communicating local culture and set up Ganpo Local Culture Media Co.,Ltd in other provinces or cities of China. Besides, it can also rely on the celebrity charm and take full advantage of media to present Ganpo local culture; secondly, it can dispatch local culture experts to other countries for academic communication, so as to broaden the horizon; thirdly, it can guide and train local culture backbones, organize them to walk out of Ganpo and give touring performances overseas. For instance, “Chinese Tea Culture Exhibition” was planned or consulted by experts of Jiangxi, “Chinese Tea Culture International Academic Seminar” was held in America in 1998 and International Tea Culture Academic Seminar was held in Hong Kong in 1999, closing ceremony of China-France Culture Year was held in Paris in 2004. All these activities have exerted some influence on foreign countries. Experts of Jiangxi Academy of Social Sciences guided the tea art performed by tea-art team. The tea art has been presented in America, Japan, Korea and Hong Kong, Macao and Taiwan for several times, which has played a role of publicizing the Ganpo local culture. We should guide and encourage cultural creative industries to widely develop foreign investments with enterprises, such as TV and movies media, press and publications, performing arts and animation, software training; lead and encourage excellent literature and art troupes to carry out 
touring or in-residence performances, so as to carry forward "Local Culture of Jiangxi" in the globe. $^{[9]}$

\section{Promoting Cultural Innovation Mechanism}

To let Ganpo local culture go out, it needs comprehensive package and excavation of boutique. Besides, the contents need to have some innovation and breakthrough. The artistic expression should be novel, such as taking full advantage of high-tech products. High-technologies can let audiences keep things in mind and keep sound in ears, such as micro films, which has strong optical, acoustic and visual effects. The local culture can haunt the audiences for a long time and become artistic classics passed from mouth to mouth. If people just pick up traditional local culture freely without innovations, it can only become the rural old's memory of the past times. However, traditional local culture needs to be inherited by generations. If people just stick to past practices during the inheritance, it will result in the situation that traditional local culture cannot find the resonance of times. Think about it, how long will be the vitality of such a local culture? In the history, porcelain of Jiangxi Jingdezhen was ever well-known and important commodity of Maritime Silk Road. Thus, it honorably becomes the pronoun of "CHINA". However, due to lack of innovations, it seems that people have already forgotten the particularity of Jingdezhen. The glory of Jingdezhen seems to be gone with the wind. Only by integrating with modern elements, can traditional local culture shines with new vitality. Such as the colored steamed bread of Shanxi Wenxi, it was one kind of traditional local food, which was ornamental food on folk weddings and funerals. However, after bold innovations of forms, it has been transformed into artistic commercial gift, which becomes present for relatives and friends. Consequently, the product has go out of Wenxi, which has been sold throughout the country, Hong Kong, Macao, Taiwan and even every other country in the world.

In conclusion, profound agricultural civilization of Ganpo has accumulated and bred profound local culture, which is the spiritual wealth and humanity of Ganpo people. However, how could the local culture be inherited, which will not be neglected or lost, but be created into the brand culture of Ganpo? It needs the common strength of Jiangxi government, the society, artists of local culture. It needs investments on capital, location, expert guidance and artist training, but also needs to devote great efforts to constantly innovating the contents and forms of local culture. Only by inheriting the traditions and highlighting the times, governmental organization, social support and public participation, can the local culture of Ganpo go out boldly and confidently. With the local flavor of Ganpo, the local culture can go out of Jiangxi and China, and then go to the world, further to actually realize that Ganpo local culture "travels through all the kingdoms and travel far away across the sea”.

\section{Acknowledgments}

This paper is the humanistic and social science program of Jiangxi universities and colleges, the title is: Research on "Going Out” Strategy of Ganpo Local Culture under the Perspective of Powerful Cultural Province, Serial No.JC1334

\section{References}

[1] Song Haifeng, Comment on Ganpo: “Agritainment” should not Loose the "Local Flavor” ,Dajiang Website, http://jiangxi.jxnews.com.cn/system/2012/08/19/012078726.shtml

[2] Cai Fujin, Yusheng Yuanfei Jiangxi Yudu, Local Culture Breeds Civilized Social Mode in Countryside, 2006-03-23 Chinese Radio Network, http://www.cnr.cn/2004news/whyl/t20060323_504183965.html

[3] Jiangxi Foreign Economic Cooperation Office, "Pingxiang Chunluo” will apply for national intangible cultural heritage protection program, Jiangxi Foreign Economic Cooperation Office Website,http://www.mofcom.gov.cn/aarticle/difang/jiangxi/200509/20050900427538.html 
[4] Deng Wang, Prosperous Development of Local Culture, China Jinagxi Website, http://ce.jxcn.cn/system/2014/12/11/013491193.shtml

[5] Hu Huilin, Cultural Industry, Higher Education Press, 2006 edition, P267.

[6] Cultural Center of Dongcheng District, Du Ran, Cultural Career of Mass needs to introduce the market operation mechanism,

People.cn, http://theory.people.com.cn/GB/49157/49165/6050640.html

[7] Xie Rongpei, "Sending Culture” Changes into "Planting Culture” Gan County positively Cultivates Local Culture, Jiangxi Department of Culture, http://www.jxwh.gov.cn/index.php/cms/item-view-id-89.shtml

[8] Yu Xinpeng, Liu Lili, Jiangxi both “Going Out” and “Attracting Foreign Investment” for Developing Cultural Career, Collectables Auction Website, http://n8539730.key.shuoqian.net/

[9] Shang Wuxing, "Going Out” : The only route of comprehensively opening to the outside world, Jiangxi Daily, Jan. 15th, 2014. 